\title{
North Atlantic Integrated Water Vapor Transport-From 850 to 2100 CE: Impacts on Western European Rainfall $\mathscr{0}$
}

\author{
Pedro M. Sousa And Alexandre M. Ramos \\ Instituto Dom Luiz, Faculdade de Ciências, Universidade de Lisboa, Lisbon, Portugal \\ Christoph C. RAIBle AND M. MesSMER ${ }^{\mathrm{a}}$ \\ Oeschger Centre for Climate Change Research, and Climate and Environmental Physics, \\ University of Bern, Bern, Switzerland \\ RICARDO TOMÉ \\ Instituto Dom Luiz, Faculdade de Ciências, Universidade de Lisboa, Lisbon, Portugal
}

JOAQUIM G. PINTO

Institute of Meteorology and Climate Research, Karlsruhe Institute of Technology, Karlsruhe, Germany

RICARDO M. TRIGO

Instituto Dom Luiz, Faculdade de Ciências, Universidade de Lisboa, Portugal, and Departmento de Meteorologia, Instituto de Geociências, Universidade Federal do Rio de Janeiro, Rio de Janeiro, Brazil

(Manuscript received 17 May 2019, in final form 21 August 2019)

\begin{abstract}
Moisture transport over the northeastern Atlantic Ocean is an important process governing precipitation distribution and variability over western Europe. To assess its long-term variability, the vertically integrated horizontal water vapor transport (IVT) from a long-term climate simulation spanning the period 850-2100 CE was used. Results show a steady increase in moisture transport toward western Europe since the late-nineteenth century that is projected to expand during the twenty-first century under the RCP8.5 scenario. The projected IVT for 2070-99 significantly exceeds the range given by interannual-interdecadal variability of the last millennium. Changes in IVT are in line with significant increases in tropospheric moisture content, driven by the concurrent rise in surface temperatures associated with the anthropogenic climate trend. On regional scales, recent and projected precipitation changes over the British Isles follow the global positive IVT trend, whereas a robust precipitation decrease over Iberia is identified in the twenty-first century, particularly during autumn. This indicates a possible extension of stable and dry summer conditions and a decoupling between moisture availability and dynamical forcing. The investigation of circulation features reveals a mean poleward shift of moisture corridors and associated atmospheric rivers. In particular, in Iberia, a significant increase in the frequency of dry weather types is observed, accompanied by a decrease in the frequency of wet types. An opposite response is observed over the British Isles. These changes imply a stronger meridional north-south dipole in terms of pressure and precipitation distributions, enhancing the transport toward central Europe rather than to Iberia.
\end{abstract}

Supplemental information related to this paper is available at the Journals Online website: https://doi.org/10.1175/JCLI-D-190348.s1.

\footnotetext{
${ }^{\text {a }}$ Current affiliation: School of Earth Sciences, University of Melbourne, Melbourne, Victoria, Australia.
}

Corresponding author: Pedro M. Sousa, ppsousa@fc.ul.pt

\section{Introduction}

Precipitation variability in western Europe is linked with the intensity and latitudinal location of water vapor transport. In this context, atmospheric rivers (ARs; Zhu and Newell 1998; Neiman et al. 2008; Dettinger et al. 2015), that is, a narrow band or corridor of high vertically integrated horizontal water vapor transport (IVT), gain particular relevance. These structures are responsible 
for local intense moisture convergence (Dacre et al. 2019), associated with the transport of high water vapor content from the tropics toward higher latitudes, and are frequently associated with heavy precipitation events in western continental coastlines of the midlatitudes (e.g., Gimeno et al. 2016; Ramos et al. 2016a). Variability in ARs characterized by the IVT has been analyzed in western Europe (e.g., Sodemann and Stohl 2013; Lavers and Villarini 2015, 2013; Ramos et al. 2015), western North America (e.g., Ralph and Dettinger 2011; Brands et al. 2017; Hecht and Cordeira 2017; Oakley et al. 2018), South Africa (e.g., Blamey et al. 2018; Ramos et al. 2018), and Chile (Viale et al. 2018), among other regions. In fact, important historical flooding events can be attributed to ARs over western Europe (e.g., Lavers et al. 2011; Lavers and Villarini 2013; Pereira et al. 2018). Likewise, severe water shortages are associated with an anomalous and persistent decrease of IVT toward these western coastal areas (Dettinger 2013; Flint et al. 2018; Sousa et al. 2018). Furthermore, atmospheric water vapor plays a crucial role in the development and the life cycle of extratropical cyclones (Ferreira et al. 2016; Eiras-Barca et al. 2018).

Taking into account the close link between the IVT and precipitation in these regions, it is of paramount importance to address how internal variability and externally forced (natural or anthropogenic) climate change influence the water vapor transport corridors in the last millennium and in the upcoming decades. Among the consensual expected impacts of global warming, changes in precipitation are expected to impose drastic socioeconomic effects (e.g., Cook et al. 2014). In this sense, changes in tropospheric moisture availability and in the water cycle due to the effect of anthropogenic induced warming have been studied by several authors (e.g., Schneider et al. 2010; Sherwood et al. 2010; Osborn et al. 2015). These studies indicate an increase in atmospheric moisture content on the large scale, due to both enhanced evaporation and additional waterretaining capacity due to higher temperatures, as expected from the Clausius-Clapeyron relation (e.g., O'Gorman and Muller 2010; Lavers et al. 2013). On regional scales, the response of precipitation to global warming is more diverse, as many areas face severe drying despite additional atmospheric water content. Several studies tried to attribute the precipitation response to either dynamical or thermodynamic changes, as the former might either amplify or reduce moisture-driven intensification related to global warming (Emori and Brown 2005; Seager et al. 2010; Santos et al. 2016; Pfahl et al. 2017; Nie et al. 2018). However, a more thorough analysis of the dynamic changes associated with moisture transport in these regions toward the twenty-first century is still needed.
The relation between such changes and extratropical cyclonic activity has also been addressed, but large uncertainties remain in future projections (Pinto et al. 2009; Harvey et al. 2015; IPCC 2019), because of contrasting effects of 1) a reduced meridional temperature gradient in the lower troposphere, 2) an increased meridional temperature gradient in the upper troposphere, 3) reduced static stability, and 4) enhanced latent heat release due to warmer and moister climate. The reduced static stability and the enhanced latent heat release lead to an intensification of cyclones, whereas the diminishing meridional temperature gradient in the lower troposphere reduces the necessity of a poleward transport of energy and weakens the cyclonic activity in the midlatitudes (e.g., Raible 2007; Raible et al. 2010; Li et al. 2014). Recently, Raible et al. (2018) used a long-term climatic simulation for the last millennium (Lehner et al. 2015) to show that no significant external forcing imprint is found prior to 1850 in terms of North Atlantic Ocean cyclone variability at interannual and decadal time scales. However, a decrease of cyclone frequencies was observed since 1850 (linked to anthropogenic warming), particularly over the Mediterranean Sea, and is expected to continue throughout the twentyfirst century (Ulbrich et al. 2009; Raible et al. 2010, 2018).

Several questions remain to be explored when analyzing long-term observed and projected trends in moisture transport, and their links and impacts in areas where annual precipitation is dominated by zonal water vapor transport, such as western Europe (Lavers and Villarini 2015). In this sense, the use of long-term and/or paleoclimate simulations (e.g., Raible et al. 2007, 2018; Cook et al. 2016; Ludwig et al. 2017; Gomez-Navarro et al. 2017) at higher temporal and spatial resolution may be crucial, allowing us to 1) frame projected changes within previous well-known climatic eras, 2) enable a finer distinction between internal and external forcing, and 3) quantify the impacts of anthropogenic influence on climatic variability. For these reasons, we will use here a long-term transient simulation spanning the period 850-2099 CE (Lehner et al. 2015). The long-term climate evolution in terms of surface variables such as air temperature, precipitation, or dynamical features (such as storm tracks) has been shown to be in reasonable agreement with simulations obtained from other PMIP3 models (Raible et al. 2014, 2018; Bothe et al. 2015), although anthropogenic warming is slightly overestimated due to a lack of negative forcing from indirect aerosol effects (Lehner et al. 2015). The availability of subdaily data at satisfying horizontal resolutions for such an extended historical period (850-2099 CE) enables us to

1) characterize the moisture transport variability dependence on near-surface temperature, 
2) assess the influence of different external forcing components acting on moisture transport in the North Atlantic by analyzing the relationship between weather types and ARs,

3) relate these shifts with regional precipitation variability and change, and

4) estimate how anthropogenic warming will impinge upon dynamical versus thermodynamical changes.

In section 2 the simulation, datasets, and methods are introduced. In section 3 we present the results for the long-term variability of moisture transport, and its relation to the regional precipitation. These results are summarized and discussed in section 4 .

\section{Data and methods}

\section{a. CESM climatic simulation}

The study is based on a long-term (850-2099 CE) transient simulation, which is performed using the Community Earth System Model (CESM 1.0.1; Hurrell et al. 2013; Lehner et al. 2015). This simulation includes modules for the atmosphere, land, ocean, and carbon cycle; relies on a state-of-the-art modified reconstruction of total solar irradiance and volcanic forcing for the last millennium simulation period; and uses the RCP8.5 forcing scenario, following the PMIP3 (Schmidt et al. 2012) and CMIP5 (Taylor et al. 2012) protocols, respectively. The only exception is the solar forcing as the amplitude between the Maunder Minimum and present time is increased by a factor of 2 relative to the PMIP3 protocol (Fig. S1 in the online supplemental material; Lehner et al. 2015). The atmospheric component uses a horizontal resolution of $1.25^{\circ}$ in longitude by $0.9^{\circ}$ in latitude and 26 vertical sigma pressure levels. For the analysis, we consider the following variables: 2-m temperature $T$, total precipitation $P_{\mathrm{TOT}}$, geopotential height $Z$, horizontal wind components $u$ and $v$, mean sea level pressure (MSLP), and specific humidity $q$-some of these variables are used to derive other meteorological fields. Further details on the climatic model and on the experimental setup of the simulation, as well as a comparison with other climatic simulations are presented in Lehner et al. (2015), Chikamoto et al. (2016), Camenisch et al. (2016), and Raible et al. (2018).

\section{b. NCEP reanalysis}

Meteorological fields from the NCEP-NCAR reanalysis are used to assess the performance of CESM in simulating near-surface temperature and moisture transport within the North Atlantic-European domain during the recent observational record. The NCEPNCAR reanalysis daily dataset (Kalnay et al. 1996) has a $2.5^{\circ} \times 2.5^{\circ}$ horizontal resolution and is available since 1948. Temperature, specific humidity, and horizontal wind series are retrieved to make a comparison with the CESM series as detailed above in section 2a.

\section{c. The vertically integrated water vapor transport}

Moisture availability and transport are characterized by the IVT. This variable is defined as a measure of the horizontal transport of specific humidity, by integrating it for a vertical column of the troposphere. For this CESM experiment, humidity vertical data were available up to the 600 -hPa level, and the IVT was computed for the column between 1000 and $600 \mathrm{hPa}$ (circa 3/5 of the vertical water content are contained within this layer; Peixoto and Oort 1992; Ralph et al. 2017), as follows:

$$
\mathrm{IVT}=\left[\left(\frac{1}{g} \int_{1000 \mathrm{hPa}}^{600 \mathrm{hPa}} q u d p\right)^{2}+\left(\frac{1}{g} \int_{1000 \mathrm{hPa}}^{600 \mathrm{hPa}} q v d p\right)^{2}\right]^{1 / 2},
$$

where $q$ is the specific humidity, $u$ and $v$ are the zonal and meridional layer-averaged wind, $d p$ is the pressure increment, and $g$ is the acceleration due to gravity.

The IVT has been widely used to track ARs. To identify ARs a tracking algorithm previously defined in Ramos et al. (2016a) is applied to the IVT data. AR detection schemes usually rely on the exceedance of IVT thresholds (e.g., Ramos et al. 2016a,b) based on present-day climatology. In this study, we consider moving thresholds (window size: 30 years) for the detection of ARs, in order to better address dynamical changes throughout the long simulation due to the external forcing. Accordingly, the removed IVT trend is essentially related to the thermodynamical forcing (due to the Clausius-Clapeyron relation). Note that future simulations of ARs using these same domains and detection algorithm, but based on a fixed IVT threshold (for the present climatology) have been already computed in Ramos et al. (2016b) resulting in significant increases in ARs frequency in both domains. Here, we aim to compare the fixed/moving threshold techniques, to address the hypothesis that the former would dictate modeled changes in ARs frequency to be a mere thermodynamical reaction of warmer and moister overall atmospheric conditions. Accordingly, such thermodynamical changes would overwhelm and possibly mask dynamical features associated with changes in $\mathrm{AR}$ structures and/or locations, inhibiting a correct assessment of the links between ARs and projected rainfall changes. ARs affecting the North Atlantic and crossing the $10^{\circ} \mathrm{W}$ meridian between $35^{\circ}$ and $65^{\circ} \mathrm{N}$ are detected, using the 85th percentile of the IVT, considering a 30-yr moving climatology. After detecting the maximum IVT at each longitude, ARs are identified as 


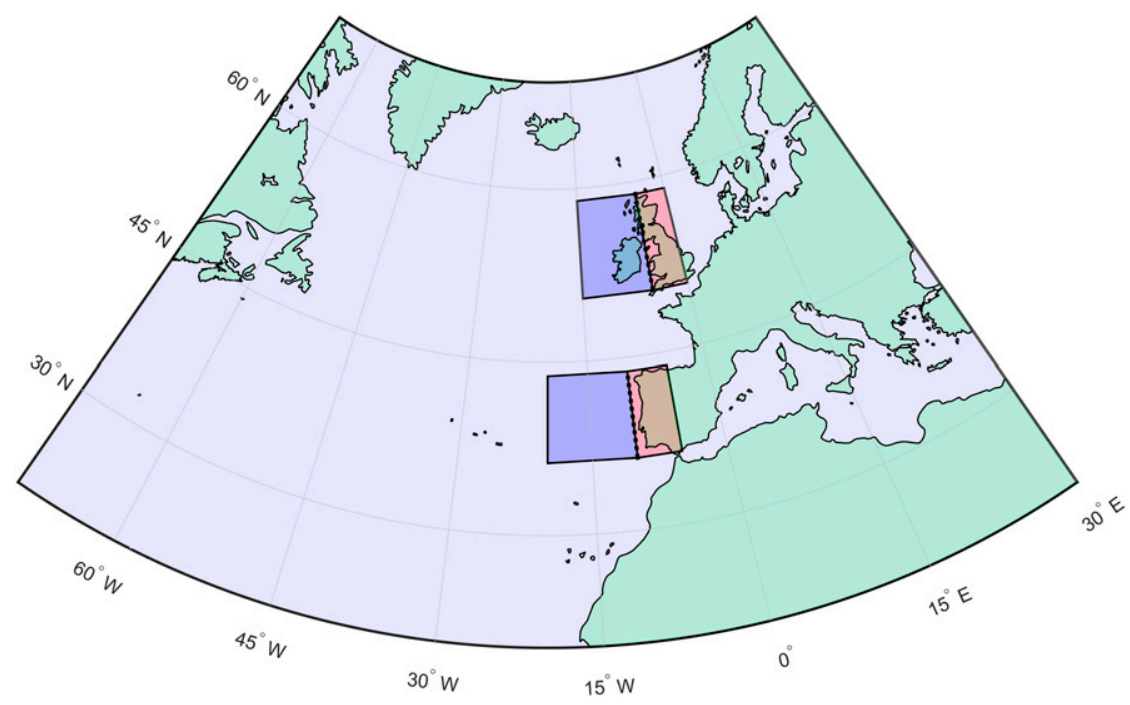

FIG. 1. Whole simulation domain $\left(20^{\circ}-70^{\circ} \mathrm{N} ; 70^{\circ} \mathrm{W}-30^{\circ} \mathrm{E}\right)$, and the regional domains considered in this study: Iberia and the British Isles. Mean regional surface temperature and vertically integrated horizontal water vapor transport (IVT) fields are computed for the blue boxes, precipitation is computed for the red boxes, and zonal IVT is computed along the dashed black lines.

contiguous structures that are at least $1500 \mathrm{~km}$ long and persist for at least three time steps. Further details on the algorithm can be found in Ramos et al. (2016a,b).

\section{d. Regional moisture fluxes}

Two subdomains are considered to analyze changes in precipitation: the British Isles and Iberia (Fig. 1). These regions are chosen to address moisture transport and precipitation changes in western Europe at distinct latitudes. Each subdomain is divided into two boxes: an oceanic box and a land box. The first box is used to check long-term changes in the mean temperature and in mean moisture fluxes advected toward the defined meridional coastlines. The land box represents the target region. Thus, we estimate changes in the mean precipitation in this box. Furthermore, the mean zonal IVT crossing each of the previously defined coastlines is calculated.

\section{e. Circulation weather types}

Circulation weather types (CWTs) are synoptic-scale patterns to characterize the atmospheric circulation occurring over a region. Here, we use an algorithm (Trigo and da Camara 2000), which is based on the method suggested by Lamb (1972). The algorithm relies on the SLP fields, using a set of indices associated with the direction and vorticity of the geostrophic flow. The geostrophic approximation is used to attribute a circulation type to each day, depending on the direction and strength of airflow and on the degree of cyclonicity. CWTs centered over western Iberia $\left(40^{\circ} \mathrm{N}, 7.5^{\circ} \mathrm{W}\right)$ and the British Isles $\left(55^{\circ} \mathrm{N}, 5^{\circ} \mathrm{W}\right)$ are computed for the entire transient simulation. To facilitate the interpretation of the resulting daily CWTs, we separate them into the respective pure directional (from north: $\mathrm{N}, \mathrm{NE}, \mathrm{E}, \mathrm{SE}, \mathrm{S}$, $\mathrm{SW}, \mathrm{W}$, and $\mathrm{NW}$ ) and cyclonic/anticyclonic (C/A) types, thus resulting in a total of 10 CWTs, using the same method as in Ramos et al. (2014). Furthermore, the directional types are grouped according to similar coherent precipitation responses (Ramos et al. 2014; Pereira et al. 2018). Thus, the following subset of grouped CWTs is considered: 1) cyclonic (C), 2) anticyclonic (A), 3) wet zonal types $(\mathrm{NW}+\mathrm{W}+\mathrm{SW}), 4)$ cold types $(\mathrm{N}+\mathrm{NE})$, and 5) warm types $(S+S E+E)$.

\section{Results}

\section{a. The link between IVT and surface temperature}

First, we analyze how the long-term variability in moisture transport in the lower troposphere is associated with fluctuations in near-surface temperatures. To address this, the interannual variability of the mean IVT and the corresponding mean surface temperature is presented for the extended winter (October-March) in the whole simulation domain (Fig. 2). Thereby, both internal variability associated with interdecadal large-scale modes and the response of the IVT to external forcing occurring since $850 \mathrm{CE}$ (including the RCP8.5 scenario) are taken into account.

The close link between surface temperature and tropospheric moisture availability is depicted in Fig. 2, 


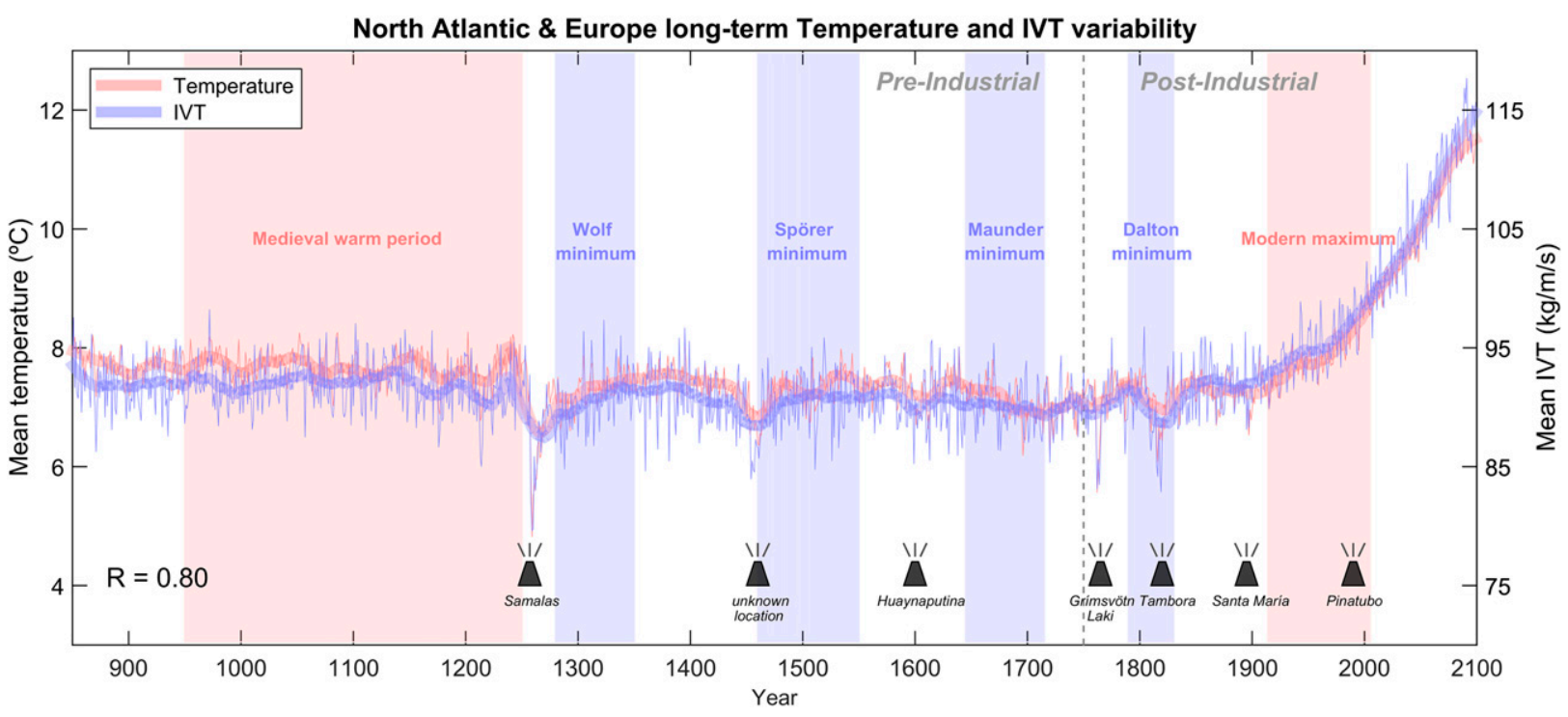

FIG. 2. Long-term variability of mean extended winter (October-March) temperature and the corresponding moisture transport for the whole domain presented in Fig. 1. Red lines show the surface temperature variability, and blue lines the IVT variability along the entire long simulation. Thin lines represent interannual variability, and thicker lines are the 30-yr smoothed series. The Spearman's correlation coefficient between yearly series is presented in the lower-left corner. Major volcanic eruptions are represented in the bottom section of the figure, and light red and blue shadings respectively denote warm and cold eras.

which shows a correlation of 0.8 (Spearman's coefficient) in terms of interannual variability. This shows the strong link between atmospheric water-retaining capacity and temperature (Clausius-Clapeyron relation). This is particularly relevant for the twenty-first century, where thermodynamical changes directly associated with the global warming trend are enhanced. The temperature (and consequently IVT) increase in the twenty-first century exceeds the amplitude of fluctuations found prior to the rise of GHGs (see online supplemental Fig. S1). In fact, while the magnitude of changes in the preindustrial era is apparently related to internal variability, the dramatic increase in temperature imposed by rising GHG concentrations strongly exceeds the previous values. To exemplify this, the variability associated with relevant warm/cold eras (e.g., Medieval Warm Period or the Maunder Minimum; Bradley et al. 2003) still falls well below the significant "jump" in mean values during the twenty-first century of the simulation (corresponding to $\sim 4.5$ standard deviations). Besides the anthropogenic factor, the largest fluctuations in the series are a response to the following external forcing functions, which can occur individually or superimposed: 1) very large volcanic eruptions and 2) significant changes in the solar forcing. For example, while a steep decrease in mean temperature and moisture availability around $1257 \mathrm{CE}$ (the end of the Medieval Warm Period) appears to be a direct response to significant volcanic forcing, in particular to the Samalas eruption (Guillet et al. 2017), the cold period found during the nineteenth century appears to be a combined response to the Dalton Minimum and the eruptions of an unknown volcano in 1809 and Tambora in 1815. Still, this period, which has the largest deviation prior to the first stages of the Industrial Revolution in the second half of the eighteenth century (hereinafter, the preindustrial period/era), corresponds only to $\sim 1.5$ standard deviations, when considering the full long-simulation variability. This is of much smaller magnitude when compared with recent decades or the projected global warming. Figure S2 in the online supplemental material focuses on the observational period from the NCEP reanalysis (since 1948). Despite a slight bias between the CESM and NCEP series, the same clear link between moisture availability and temperature at interannual scales can be appreciated there, even after removing trends from the series.

\section{b. Regional precipitation changes}

As described in section 2d, two regional subdomains (British Isles and Iberia) are considered for a more detailed analysis, in particular aiming to identify different responses in precipitation depending on latitude. As so, links between the extended winter IVT and temperature time series in each domain are assessed similarly to section 3a.

As depicted in the two panels in Fig. 3, both the enhancement in recent decades and the projected increase 
a)

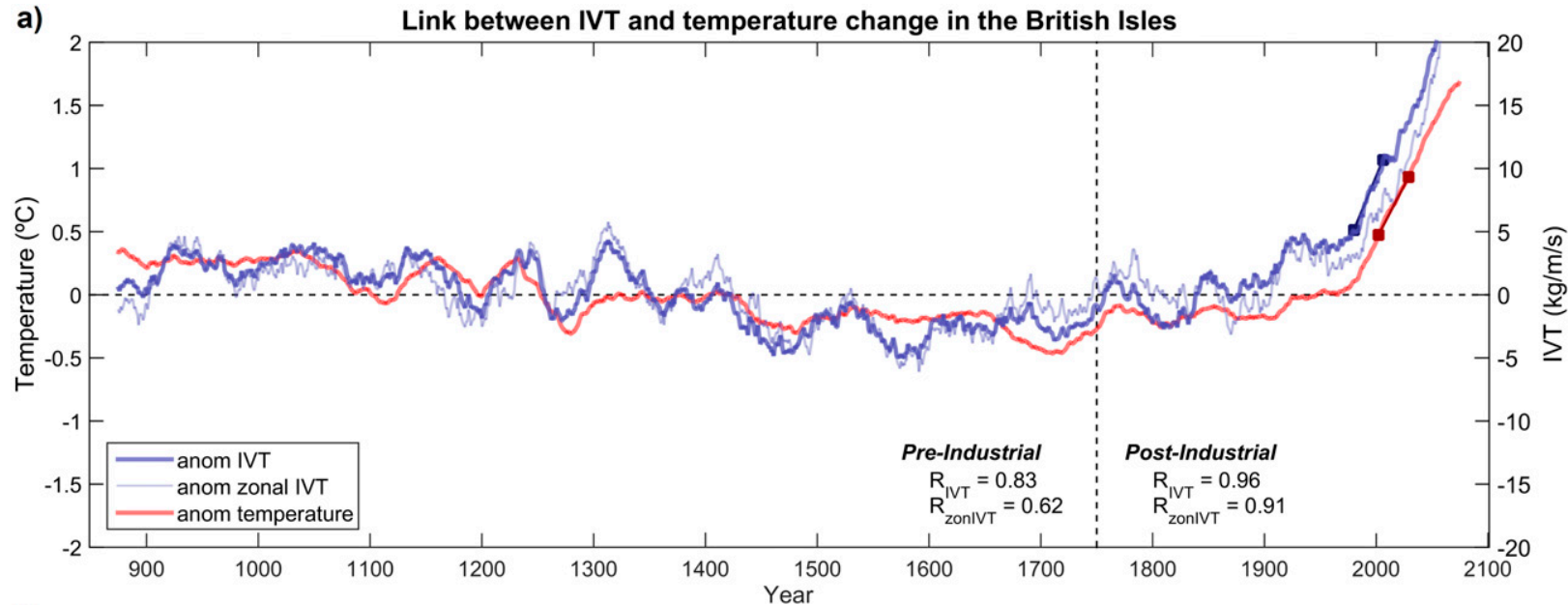

b)

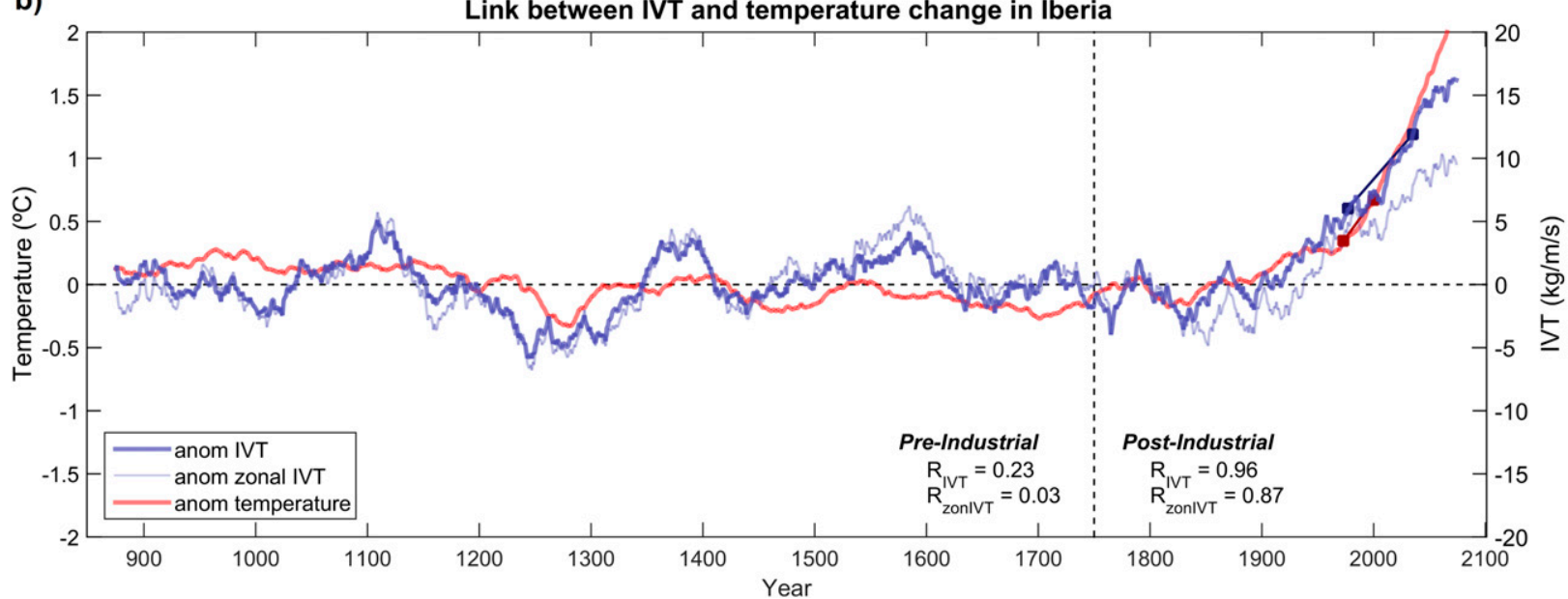

FIG. 3. Variability of the near-surface temperature anomalies (red) and IVT (blue) over the (a) British Isles and (b) Iberia regional boxes during extended winter months (October-March), relative to the preindustrial period. Dark- and light-blue curves correspond to the mean IVT in the oceanic box and the zonal IVT along the coastline, respectively, as defined in Fig. 1. The straight lines superimposed on the series represent the estimated period of emergence of the signals, by considering the exceedance of the maximum preindustrial variability (and twofold). The Spearman's correlation coefficients between temperature series and IVT series are estimated for the pre- and postindustrial periods separately.

in moisture transport are likely linked to warming, which is significant also at the regional scales. In fact, the emergence of the IVT and temperature signals associated with tropospheric warming (when taking the preindustrial period as a reference) is simulated to be already underway (straight lines and squares in Fig. 3). Accordingly, a sharp and steady rise of temperature and IVT in oceanic regions close to the British Isles and Iberia is expected to continue (as well as for overall western Europe, as previously shown in Fig. 2). Despite the unambiguity of these long-term trends, which is well reflected in the correlation coefficients found for the postindustrial period (correlation $\approx 0.9$ ), regional fluctuations in moisture transport appear to represent internal variability at shorter time scales. This is particularly notable for Iberia, where the link between the mean IVT (and zonal IVT) and temperature in the preindustrial period is quite low (Fig. 3b). In the British Isles, despite also being lower than during the anthropogenic forced period (Fig. 3a), this connection is still relevant (correlation $>0.5$ ). Results show a relatively stable overall mean tropospheric moisture content prior to human induced warming. Accordingly, the changes in regional transport of moisture toward western Europe (in particular in southernmost areas) during this period mainly depend on internal variability, that is, on specific regional and/or synoptic changes in atmospheric dynamics.

In Fig. 4, the link between the IVT regional series and precipitation anomalies over the British Isles and Iberia 
a)

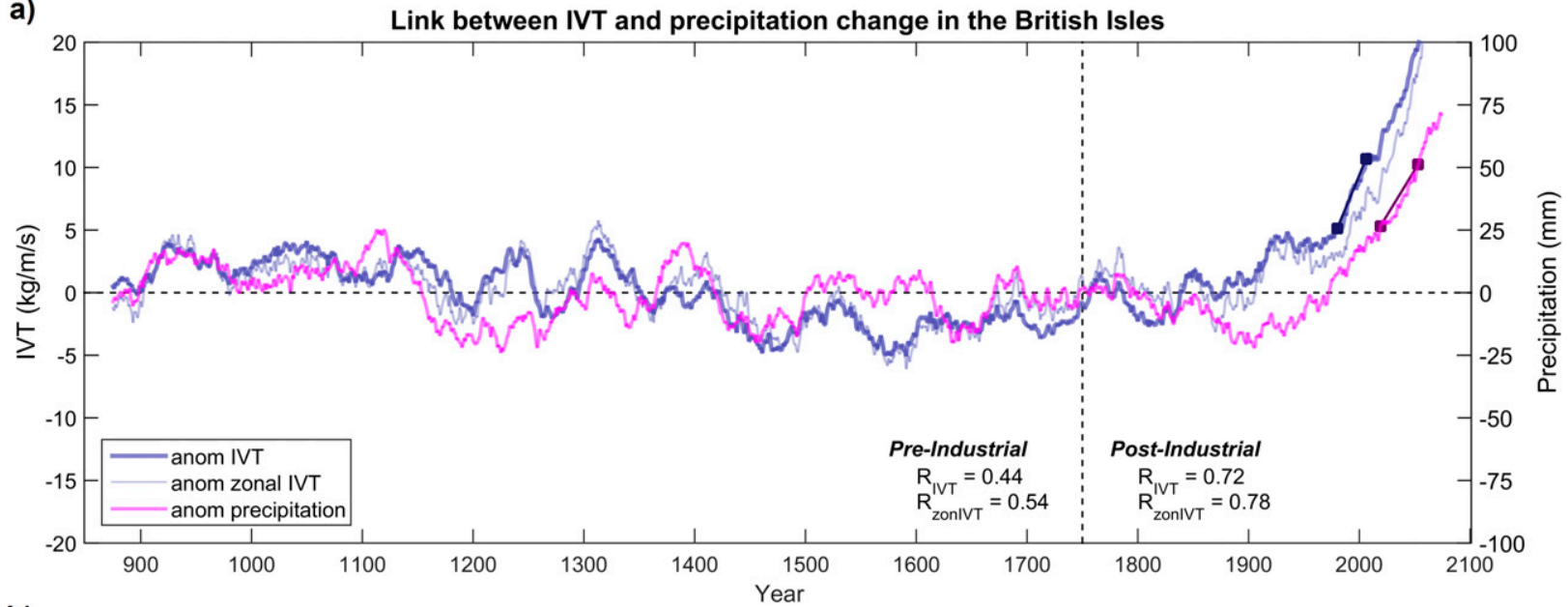

b)

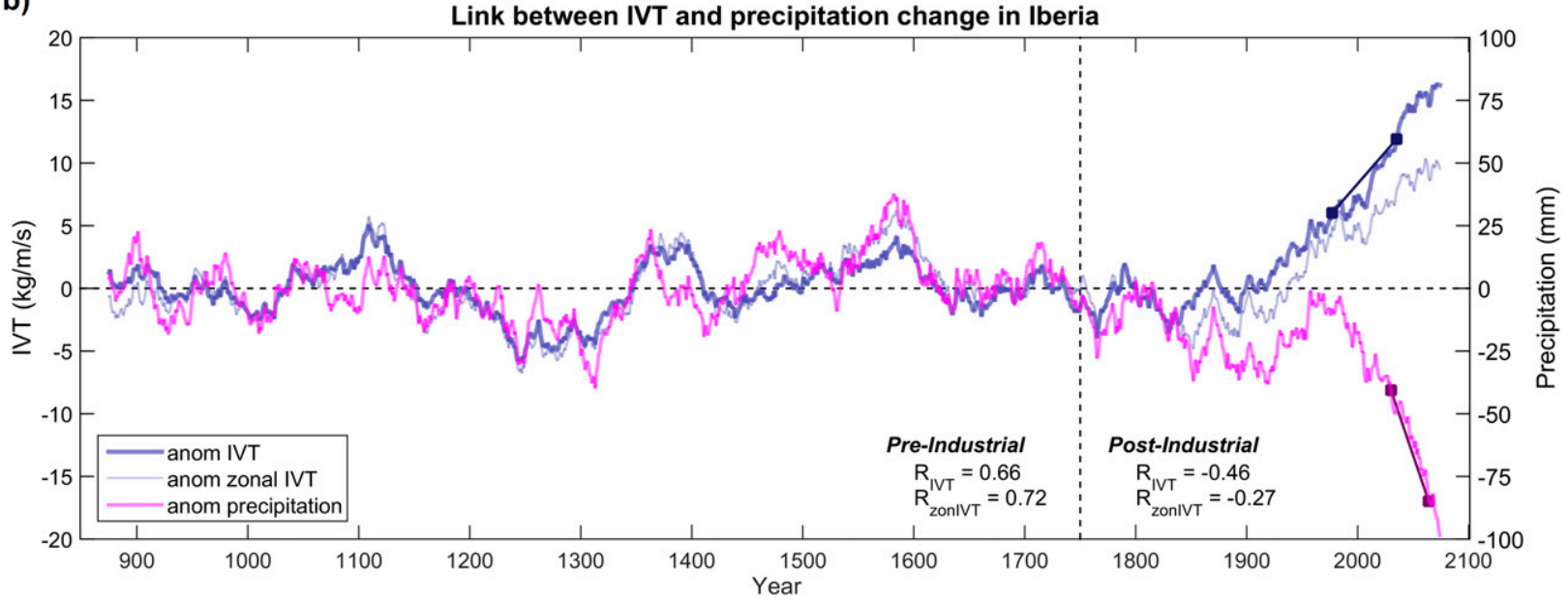

FIG. 4. As in Fig. 3, but for the variability of the IVT (blue) and total precipitation (magenta) anomalies. The Spearman's correlation coefficients between precipitation series and IVT series are estimated for the pre- and postindustrial periods separately.

is analyzed. In the case of the northernmost domain (British Isles; Fig. 4a), a positive link between precipitation anomalies and IVT anomalies persists throughout the entire simulation. While the higher values of the correlation coefficient after the industrial revolution clearly reflect the concurrent sharp positive trend in both series, the lower correlation found once again in the preindustrial era reveals how precipitation interannual variability results from internal variability. This variability relates to storm-track frequency/location, and other dynamical factors such as the occurrence of atmospheric blocking, and interdecadal oceanic oscillations. Despite this, the series for this domain reflect an overall close association between higher moisture transport toward the British Isles and wetter conditions and between lower moisture transport toward the British Isles and drier conditions. A similar (and even stronger) link is found during the preindustrial period for Iberia (Fig. 4b). However, a striking decoupling pattern is obtained for this region when computing links for the $1750-2099$ period $(R \approx-0.5)$, reflecting a very sharp decrease in precipitation during the twenty-first century, in contrast to the steady rise in tropospheric moisture content and transport associated with low-level warming. In fact, the correlation is strongly negative when considering only the period after $2000(\sim-0.90)$. However, it must be noted that the emergence times due to warming signal for precipitation series are simulated to occur later (closer to midcentury), when compared with IVT and temperature series. Thus, early twenty-first-century changes, and consequently present conditions, still marginally fall within the observed variability although they are now close to emergence, in line with the observational evidence of rainfall decline in the region (Becker et al.2013). At this point, it is safe to say that the model projection shows a decrease in precipitation in southern Europe despite the thermodynamically driven increase in atmospheric 
a)

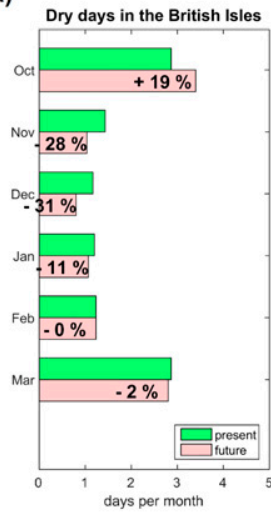

c)

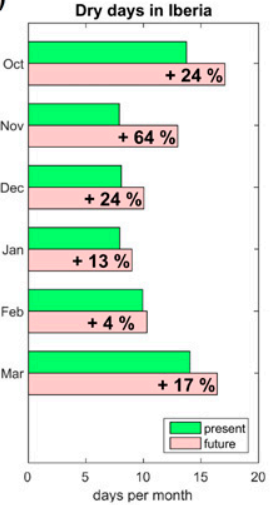

b)

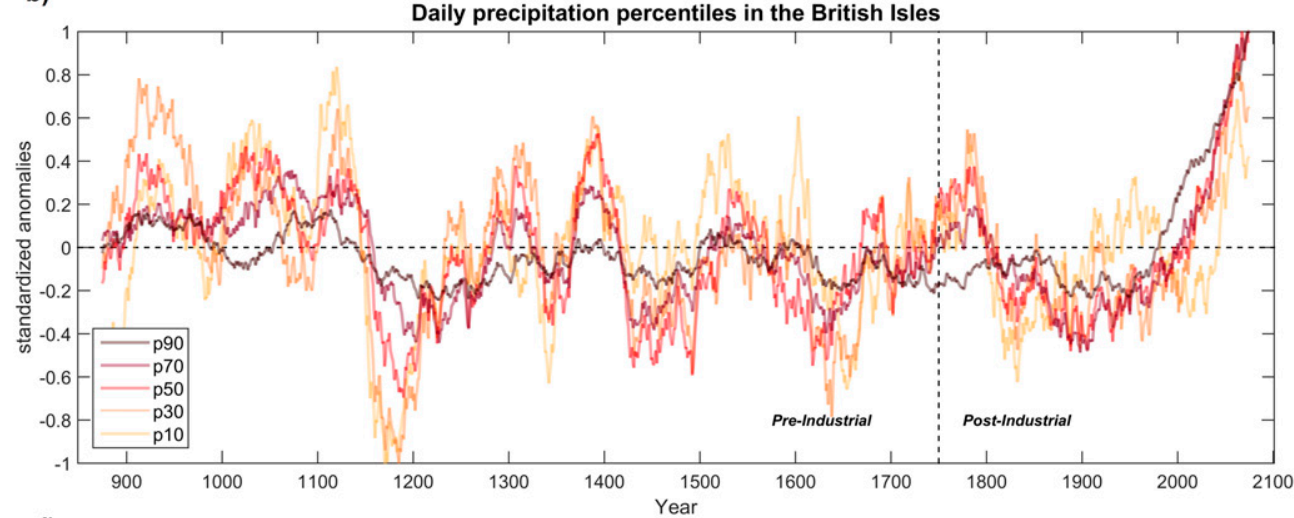

d)

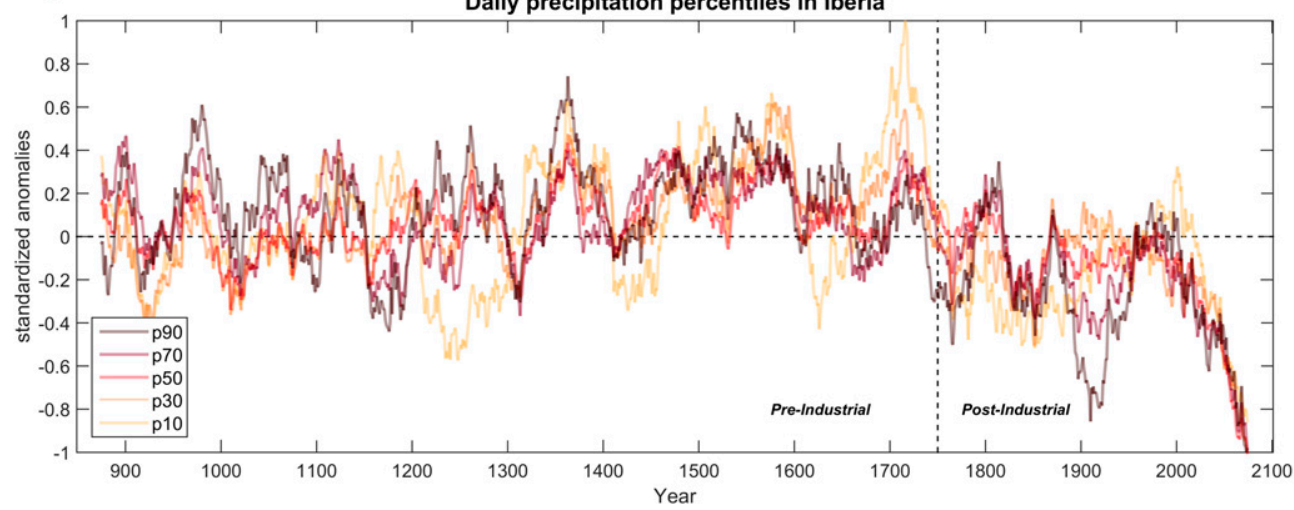

FIG. 5. Number of dry days comparing present climate (green bars; 1981-2010) and future projections (light-pink bars; 2070-99) for the (a) British Isles and (c) Iberia. Also shown is the variability of the standardized mean anomalies of different precipitation percentiles over the (b) British Isles and (d) Iberia regional boxes throughout the long-simulation period-darker curves correspond to more extreme precipitation. All panels refer to extended winter months (October-March).

water content. The dynamical changes possibly responsible for this striking result will be further discussed in section $3 \mathrm{c}$.

The highly contrasting north-south dipole in terms of precipitation trends in western Europe is also well illustrated in the changes of precipitation distributions. Figures $5 \mathrm{a}$ and $5 \mathrm{~b}$ show not only an increase in all percentiles of the precipitation distribution over the British Isles, but also a very slight decrease in the number of dry days $(<1 \mathrm{~mm})$ in almost all extended winter months when comparing the periods 1981-2010 and 2070-99 (Fig. 5a). October is the only month with an increase in the number of dry days. Furthermore, heavier precipitation classes show the largest increases over the British Isles, as the curves for higher percentiles illustrate. For Iberia (Figs. 5c,d), precipitation decreases are found for all percentiles, in particular in the moderate precipitation classes $(30<$ percentile $<70)$. This decrease in the frequency of occurrence of the most relevant precipitation classes, together with an increase in the number of dry days in extended winter months, explains the expected negative trend in total precipitation in the region. Furthermore, the largest increases in the number of dry days in Iberia are found outside central winter months and a severe shortening and delay of the rainy season is expected as the twenty-first century progresses. In fact, the increase in the number of dry days in October, November, and December $(24 \%, 64 \%$, and $24 \%$ ) is larger than those found from central January to March (Fig. 5c). Taking into account that October is the only month with a similar result over the British Isles, the analysis further suggests an overall delay in the intra-annual precipitation cycle over western Europe, as a result of prolonged summer conditions extending toward the generally wet autumn months.

\section{c. The roles of dynamical and thermodynamical forcing}

The projected changes associated with global warming were addressed above mostly from a thermodynamical point of view, revealing a general increase in moisture transport. This reflects the ongoing surface warming trend, and is concurrent with increases in oceanic evaporation, plus higher water-retaining capacity in the lower troposphere. However, it is unclear why this does 
a)

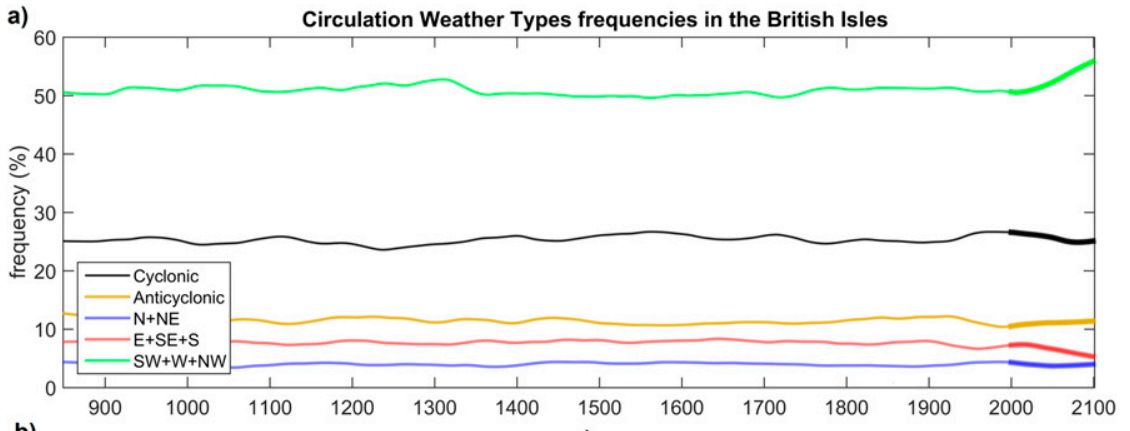

b)
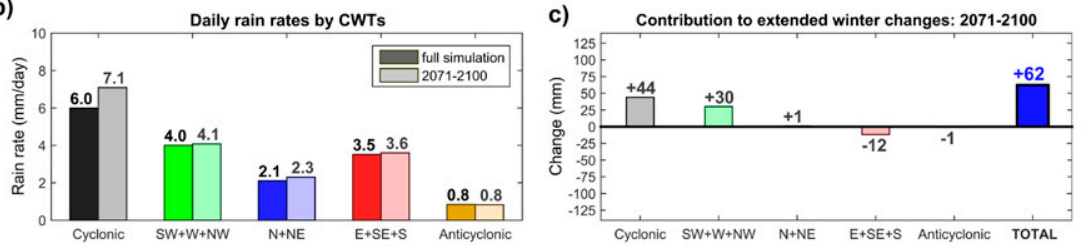

d) Circulation Weather Types frequencies in Iberia

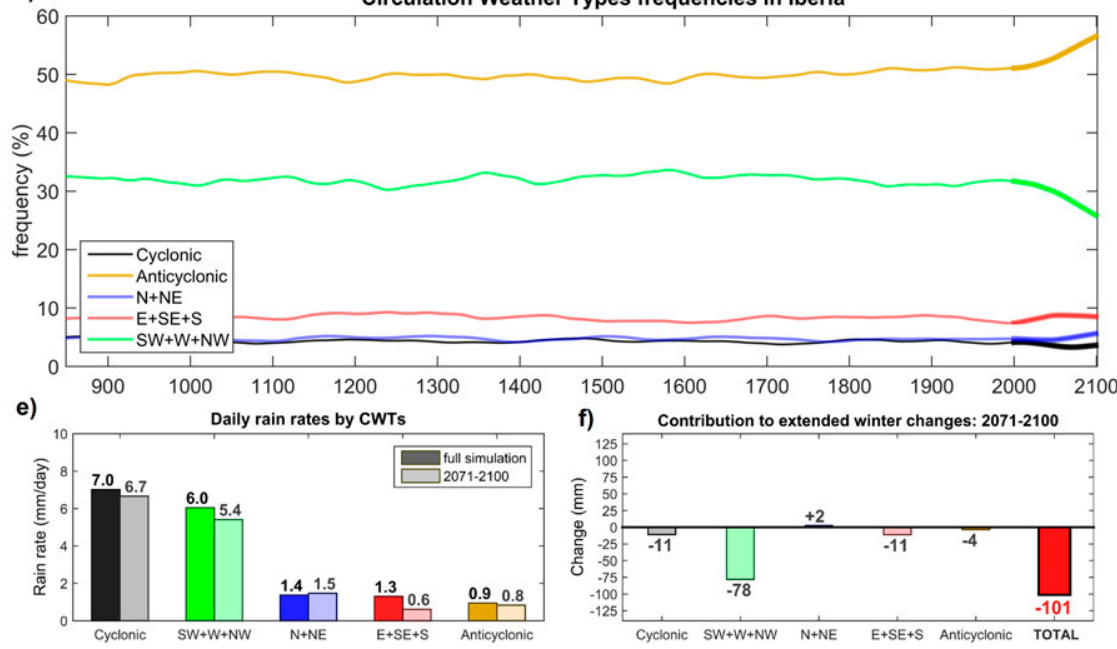

FIG. 6. (a) Changes in the frequency of CWT for the British Isles during extended winter months (October-March) throughout the long-simulation period. Directional weather types are grouped according to typical coherent surface responses. The thicker curves highlight changes occurring during the twenty-first century. A 30-yr running mean has been applied to the series. (b) Daily precipitation $\left(\mathrm{mm} \mathrm{day}^{-1}\right)$ associated with each group of CWTs: darker bars refer to the 1981-2010 climatology, and lighter bars refer to the 2070-99 projected climatology. (c) Changes (2070-99 minus 1981-2010) in total extended winter precipitation associated with each group of CWTs, and the overall net change (labeled TOTAL). (d)-(f) As in (a)-(c), but for Iberia.

not lead to an increase in precipitation in all areas (cf. Fig. 4b). In this section, we address these changes from a dynamical perspective, analyzing the distinct large-scale and regional dynamical features.

The analysis of CWTs shows that the intrinsic interannual/decadal variability in their frequencies of occurrence is overwhelmed by the large changes projected for the twenty-first century (highlighted by the thicker lines, Figs. 6a and 6d). This fact suggests a significant dynamical response to the global warming signal. To facilitate the interpretation, directional types are grouped according to similar coherent precipitation responses (as explained in section $2 \mathrm{e}$ ). The daily precipitation rate associated with each group of CWTs are shown in Figs. $6 \mathrm{~b}$ and $6 \mathrm{e}$, pointing to the cyclonic (in dark gray) and those with a westerly component (in green) types as the most efficient in terms of precipitation in both regions. Despite the slightly higher efficiency of cyclonic types, the much larger combined frequency of wet westerly types implies that these CWTs correspond to the most contributing for seasonal precipitation. As shown in Figs. 6a and 6d, the frequencies 
a)
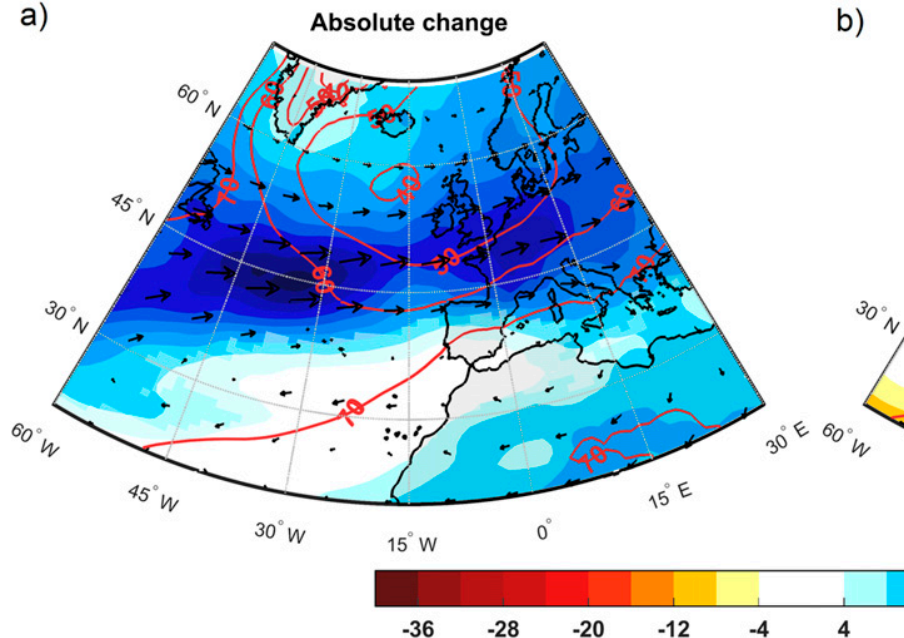

b)
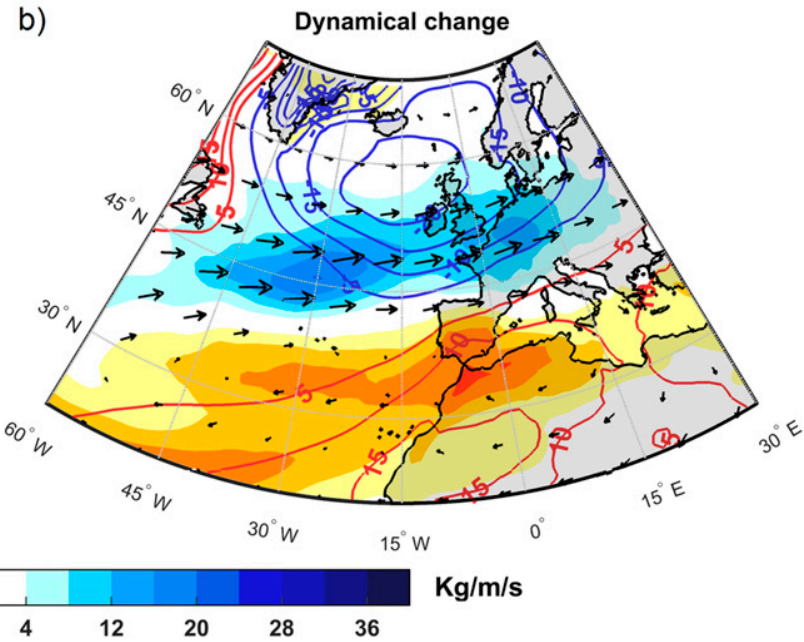

FIG. 7. Projection for changes in the mean moisture transport during extended winter (2070-99 minus 1981-2010) [shading represents changes in IVT $\left(\mathrm{kg} \mathrm{m}^{-1} \mathrm{~s}^{-1}\right)$; red and blue contours respectively represent increases and decreases in the 1000-500-hPa geopotential height thickness; arrows represent the change in the IVT direction and magnitude], showing (a) projected absolute changes, with transparent shading denoting areas where changes are not significant at the $98 \%$ level of confidence after performing a two-sample Kolmogorov-Smirnov test, and (b) changes in the previous fields attributable to dynamical modifications, i.e., after removing the moisture increase associated with the warming signal.

of wet types show highly contrasting trends for the British Isles (rising) and Iberia (decreasing). Consequently, their changes can explain a large fraction of the observed precipitation trends previously shown in Figs. 4 and 5. This is particularly notable in Iberia, where changes in wet directional types are of larger magnitude than changes in cyclonic types, thus being responsible for $\sim 3 / 4$ of the projected precipitation decrease (Fig. 6f). In the British Isles, the opposite trend explains nearly half of the projected increase in precipitation (Fig. 6c). In this region, a significant increase in precipitation associated with the cyclonic type makes this the most contributing CWT to future changes. On the contrary, daily precipitation rates associated with cyclonic types decrease in Iberia, as well as their frequency of occurrence, thus also intensifying the drying trend in this region. These results are in line with those presented by Santos et al. (2016), where a set of 22 models was used to access the uncertainty associated with weather types. Their work has shown how increases in the frequency of dry types are expected to impinge on rainfall declines in southern Europe.

Thus, projected changes in precipitation for wet CWTs suggest an increased efficiency for precipitation over the British Isles, and a decreased efficiency over Iberia. Furthermore, in the latter case, a sharp increase is also found in the anticyclonic type (nearly $10 \%$ ) toward 2100 (Fig. 6d). A rise in the frequency of days presenting anticyclonic conditions in the lower atmosphere (often associated with increased subtropical ridges activity in the midtroposphere) in southernmost areas will inhibit vertical upward motion, and thus the conversion of tropospheric water content into actual precipitation, and thus it will aggravate the projected drying trend.

To highlight these changes in a large-scale perspective, projected future changes in moisture transport and pressure distribution are shown in Fig. 7. The total projected changes in moisture transport and geopotential height thickness between future and present climates are shown in Fig. 7a. An overall increase for both variables is evident in the twenty-first century, as expected because of the Clausius-Clapeyron relation and the thermal expansion of the troposphere. The individual absolute IVT and geopotential height thickness climatologies for present day and future are presented in Fig. S3 of the online supplemental material, showing that these changes are not equally distributed, with larger (smaller) increases in IVT (thickness) north of $45^{\circ} \mathrm{N}$. In fact, in large parts of Iberia and of the oceanic area to its southwest, these total changes in moisture content are not significant relative to present conditions, despite the thermodynamical contribution of a steep temperature rise by $2070-99$.

Taking this into account, the changes directly attributable to warming can be estimated. In terms of the $1000-500-\mathrm{hPa}$ geopotential height thickness, this is simply done by removing its mean projected change in the whole simulation domain (presented in Fig. 1) from the absolute change. For the IVT we followed the 
method by O'Gorman and Muller (2010), where the latitudinal rate of change (by each $1^{\circ} \mathrm{C}$ increase) on variables related to specific humidity is estimated according to the Clausius-Clapeyron relation. These approximations are applied to each grid point, thus estimating the IVT and geopotential thickness changes due to dynamical factors (Fig. 7b). A clear north-south dipole arises for both variables: 1) an increase in moisture transport from the Atlantic is found toward France and the British Isles and a decrease is found toward Iberia, and 2) a decrease in geopotential height thickness is expected north of $45^{\circ} \mathrm{N}$ and an increase is expected south of $45^{\circ} \mathrm{N}$. These dynamically induced changes are also in line with those identified for precipitation over the area based on the CMIP5 ensemble (Santos et al. 2016). This dipole pattern illustrates an increase in the zonal flow and moisture advection toward central Europe, and much more stable and dry conditions over Iberia, associated with increased atmospheric ridge activity. This poleward displacement of subtropical high pressure areas particularly affects the southern half of Iberia. In a warming climate, while the projected dynamical changes exacerbate the simultaneous thermodynamical changes expected over the British Isles, they tend to cancel out in Iberia, thus explaining the highly distinct regional changes in projected precipitation, as previously described. In addition, over Iberia, the Clausius-Clapeyron relation implies an overall decrease in near-surface relative humidity, further undermining precipitation events.

To further emphasize the balance between dynamical and thermodynamical changes associated with the warming trend, we compared statistics for ARs crossing the $10^{\circ} \mathrm{W}$ meridian during three distinct climatic periods: 1) the preindustrial period (until the second half of the eighteenth century), 2) present climate (1981-2010), and 3) future climate (2070-99). To better frame the analysis on ARs, the contribution of each group of CWTs for the occurrence of different rainfall intensities is estimated, considering only days on which ARs are present (Figs. 8a,b). For the British Isles, westerly flows are the most contributive to lighter rainfall and cyclonic flows are the most contributive to heavier rainfall in days with ARs. On the other hand, zonal flows dominate all rainfall categories in Iberia. This occurs as a large fraction of AR-related precipitation in Iberia is associated with cyclones passing farther to the north, with moisture corridors associated with fronts affecting the peninsula under a westerly or southwesterly flow (Ramos et al. 2015). Other CWTs tend to inhibit significant rainfall occurrence, even under the presence of high moisture content associated with ARs. For example, anticyclonic CWTs reveal very low rainfall efficiency for moderate and heavy precipitation regimes in Iberia (Fig. 8b), while they are associated with light precipitation AR days. This highlights the role of regional static stability in inhibiting the conversion of high moisture content associated with ARs into effective rainfall in this region.

The latitudinal frequency of occurrence of ARs crossing the $10^{\circ} \mathrm{W}$ meridian is presented in Figs. $8 \mathrm{c}-\mathrm{e}$, and the difference between future and present ARs is summarized in Fig. 8f. Although relative changes are not particularly striking, a slight northward shift in the preferred latitude for AR occurrence is projected. Despite this modest latitudinal shift, its cumulated effect with a significant increase in AR days under anticyclonic CWTs in Iberia, plus a decrease in AR days under westerly flows, explains the significant decrease in AR-related precipitation occurring in the region (Fig. 8f). In fact, the mean location of moisture corridors is already somehow marginal for this region under current climate conditions (cf. Fig. S3). Since ARs are by definition very narrow structures, a slight poleward shift of these moisture corridors north of $45^{\circ} \mathrm{N}$ associated with enhanced high pressure over Iberia should impinge relevant changes in precipitation totals over the region (Ramos et al. 2015). This projected drying pattern is particularly notable over the southwestern sectors of Iberia (Fig. 8h) and is in line with the latest regional climate change assessment for Spain (Francés et al. 2017).

Contrariwise, relevant increases in rainfall are enhanced farther north, in areas that are positioned northward to the mean location of ARs nowadays $\left(>50^{\circ} \mathrm{N}\right)$. Taking the large increase in mean tropospheric moisture content into account, statistics show a sharp increase in the mean intensity of ARs (Fig. 8g) as a result of much higher mean IVT values. In this sense, the combined effect of overall moisture increase and the poleward shift in ARs' mean latitude should explain AR-related precipitation increases in the British Isles, as there are no significant changes projected in terms of CWTs frequency during AR days (Fig. 8f). Summarizing, the analysis of changes in ARs' activity in the eastern Atlantic area (thus affecting western European coastal areas) seems to be in line with the main synoptic and thermodynamic features discussed above, all pointing to a highly contrasting north-south response in terms of changes in precipitation.

\section{Conclusions and discussion}

The long-term variability of the lower tropospheric water vapor transport in the North Atlantic toward coastal areas of western Europe is analyzed using IVT 
a)
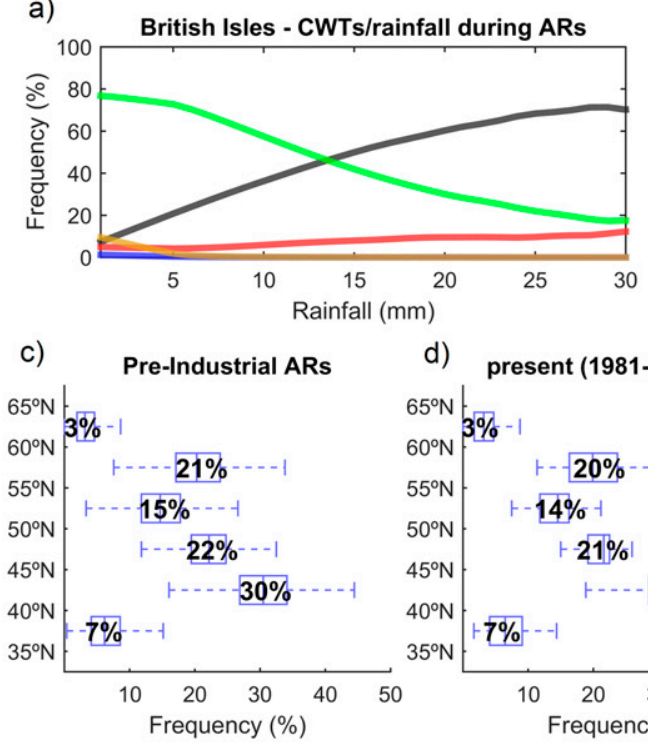

d)

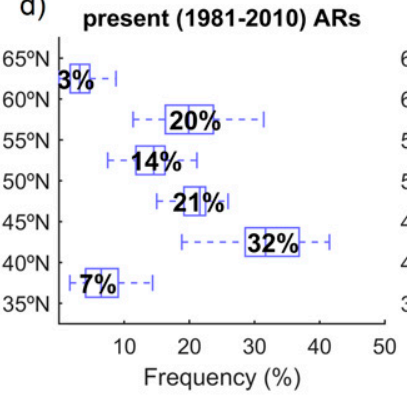

g)

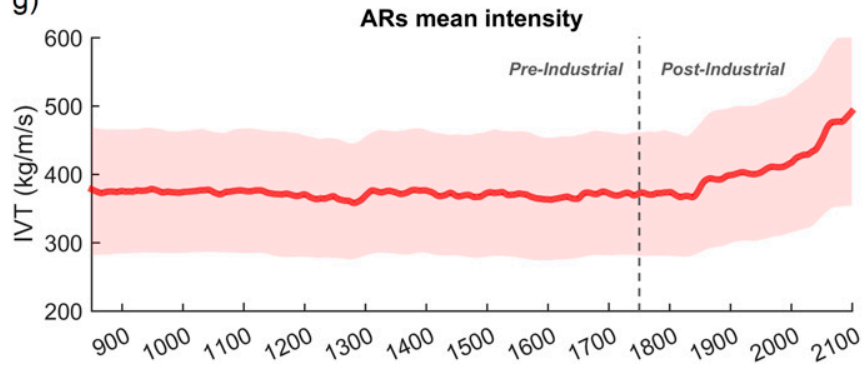

ARs statistics
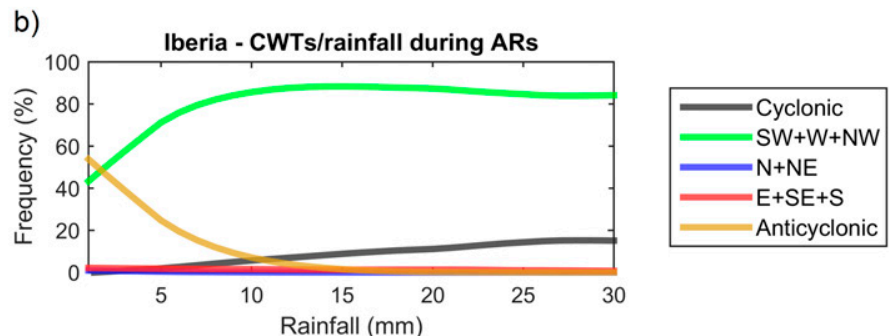

e) future (2071-2100) ARs
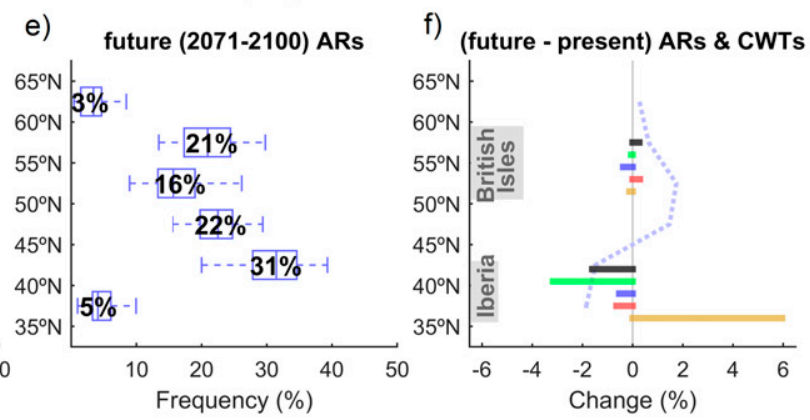

h)

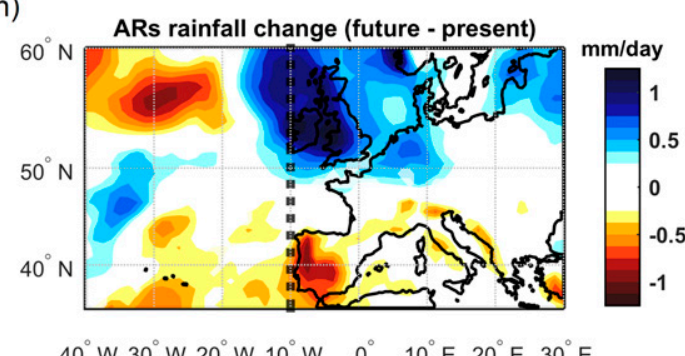

FIG. 8. Statistics for ARs in the North Atlantic crossing the $10^{\circ} \mathrm{W}$ meridian during extended winter, for distinct climatological reference periods in the long-term CESM simulation: the contribution of CWTs in terms of relative frequency for distinct daily precipitation intensities $(>1 \mathrm{~mm})$, considering only days with ARs in the (a) British Isles and (b) Iberia; boxplots for the frequency of occurrence of ARs in $5^{\circ}$ latitudinal windows for the (c) preindustrial, (d) present, and (e) future climates; (f) the difference between (e) and (d) (dashed line) and future changes in CWTs during ARs for each regional box (bars) (shaded text boxes highlight the latitudes where the British Isles and Iberia are located); (g) mean intensity of ARs crossing the $10^{\circ} \mathrm{W}$ meridian throughout the entire simulation (the envelope corresponds to 1 std dev); and (h) spatial changes in mean daily precipitation during days with ARs.

fields from a CESM transient simulation (850-2099 CE). Moreover, the related impacts on precipitation over Iberia and the British Isles are addressed, as well as the main atmospheric dynamics related to the observed/ projected future changes. The main outcomes of this work may be summarized as follows:

1) There is generally a close relationship between the variability of near-surface temperature and moisture availability in the lower troposphere.

2) Established on the previous relation, a clear increase in moisture availability and transport in the northern Atlantic since the nineteenth century is attributed to the global warming signal.

3) A significant concurrent increase in both temperature and the IVT is projected in a warmer world.
4) The response of precipitation to increases in temperature and moisture availability is nonlinear. While recent precipitation trends and future projections over the British Isles reflect increases in temperature and moisture availability, the response of precipitation to these two variables over Iberia is decoupled since the late twentieth century; that is, increasing IVT is accompanied by a decrease in precipitation.

5) The drying trend over Iberia can be explained to a large extent by the corresponding decrease in the frequency of wet CWTs and increase in the frequency of dry CWTs, with an associated increase in stable anticyclonic patterns in southernmost sectors.

The significant warming trend in the last two centuries led to an increase in tropospheric moisture content. This link between near-surface temperature and 
IVT simulated by the CESM model during the observational record is also observed for the NCEP reanalysis, for both nondetrended and detrended series. Also, the temperature trends in the CESM simulation following the RCP8.5 emission scenario are within the range of the CMIP5 simulations (e.g., Lehner et al. 2015). Furthermore, Alexander et al. (2018) also used the CESM model for sea surface temperature projections, highlighting that it has one of the best performing oceanic modules. Accordingly, the long-term close relation and dependence of moisture transport on near-surface temperature should be adequately represented by CESM. Taking this into account, projections for the twenty-first century point to a steep rise in IVT over the North Atlantic when compared with the past and present conditions. This increase clearly surpasses the variability observed during pre- and postindustrial periods due to both internal and external forcings (reaching $\sim 4.5$ standard deviations) and is consistent and directly associated with the unequivocal global warming trend (IPCC 2019). Regarding the external forcings imposed to the model simulation, the prescribed volcanic forcing for the last millennium seems to be the main driver of the largest fraction of the variability observed prior to anthropogenic warming.

Previous studies have addressed changes in moisture content and in the water cycle due to global warming (O'Gorman and Muller 2010; Sherwood et al. 2010; Lorenz and DeWeaver 2007), estimating the expected humidity increase rates due to warming based on the Clausius-Clapeyron equation. A rough estimate of $\sim 7 \%{ }^{\circ} \mathrm{C}^{-1}$ has been relatively consensual among several authors, but more recently Skliris et al. (2016) have proposed tropospheric rates below $5 \%{ }^{\circ} \mathrm{C}^{-1}$. Furthermore, an important dependence on latitude has also been reported (O'Gorman and Muller 2010), as considered in this work. Also, Byrne and O'Gorman (2018) have shown that declining relative humidity over land is beginning to emerge from observations. Such discrepancies among methods point out that the derived estimations of thermodynamical versus dynamical changes should always be addressed with caution. On the other hand, changes in frequencies of ARs affecting western Europe have also been studied (e.g., Lavers et al. 2013; Ramos et al. 2016b), pointing to large increases at higher latitudes (e.g., the British Isles), and more mixed trends in the south (e.g., Iberia). In these studies, ARs are calculated on the basis of fixed thresholds calibrated with present climatic conditions. To unfold the effect of relying on fixed/moving IVT minimum thresholds for AR detection, and to take into account the future thermodynamically driven change of the IVT during the twenty-first century, we used the latter approach for the detection of ARs. We argue how this could correct potential overestimations in future AR frequencies associated with the use of a stationary IVT threshold (a result that is not coherent with projected rainfall trends, particularly over Iberia). Our results show a slight increase in AR frequencies in regions north of $45^{\circ} \mathrm{N}$ by the late twenty-first century, and a decrease southward, associated with a rise in the number of anticyclonic days over Iberia. Concurrently, a large increase in the intensity of the ARs is expected due to the much higher mean IVT values resulting from thermodynamical changes. These outcomes are generally in line with the work from Espinoza et al. (2018), who estimated that while there are $\sim 10 \%$ fewer ARs in the future, these will be $\sim 25 \%$ longer and $\sim 25 \%$ wider and exhibit stronger IVTs for end-of-the-century RCP8.5 conditions. However, it must be taken into account that models exhibit systematic negative biases across the midlatitudes in replicating historical AR frequency $(\sim 10 \%)$, zonal IVT $(\sim 15 \%)$, and meridional IVT ( $\sim 25 \%$ ), with sizable intermodel differences (Espinoza et al. 2018; Ramos et al. 2016b). Results suggest that the western United States, northwestern Europe, and southwestern South America exhibit considerable intermodel differences in projected changes in ARs (Espinoza et al. 2018). While an expected strengthening of future ARs appears to be consensual, the spread in their expected frequency and preferential location reveals how different approaches for AR detection (as discussed in this work) may lead to uncertainties depending on climatological benchmarks (Brands et al. 2017).

We also show how the changes found in circulation patterns and in AR metrics agree with future changes in atmospheric circulation at the synoptic scale, in particular those attributable to purely dynamic factors. By removing the changes in IVT and pressure distribution attributable to thermodynamical factors, we show that a pressure dipole pattern will tend to increase moisture transport north of $45^{\circ} \mathrm{N}$ and inhibit the transport toward southern Europe. The magnitude of this decrease of moisture transport due to dynamical features in southernmost regions is smaller than the increase directly related to warming, so the overall net change will be positive [in agreement with Pfahl et al. (2017)]. Still, as the Clausius-Clapeyron relation shows, the higher water-retaining capacity of a warmer atmosphere partially explains precipitation decreases at lower latitudes, despite higher absolute moisture content (e.g., Santos et al. 2016). On the other hand, a large fraction of this reduction is attributable to an increase of stable anticyclonic weather regimes south of $45^{\circ} \mathrm{N}$, and a subsequent decrease in vertical forcing mechanisms. In fact, the frequency and efficiency of wet CWTs in Iberia decreases 
significantly, which is consistent with the expected expansion of the subtropical high pressure systems associated with the Hadley cell, under a warming climate (Lu et al. 2009; Staten et al. 2012, 2018). However, the mechanisms related to this expansion are still quite debated, in particular the coupling between subtropical expansion/drying and sea surface temperatures, increase in moisture content, subtropical baroclinicity, or landsea warming contrasts, among other variables (e.g., He and Soden 2017; Chemke and Polvani 2019), and should be further explored using multimodel ensembles.

Ulbrich et al. (2009) and Raible et al. (2018) pointed to an overall decrease in the number of days with cyclones in the studied domain. However, this apparent decrease in cyclonic frequency could also be partially associated with a faster westerly flow associated with an enhanced and more zonal jet stream over the eastern North Atlantic and western Europe (e.g., Pinto et al. 2009; Zappa et al. 2015). Furthermore, this decrease is opposite to IVT trends in northernmost areas, where we show that wet CWTs are expected to become more efficient in producing significant precipitation.

Accordingly, our analysis on changes in precipitation has shown a clear increase in all precipitation classes in the British Isles, while a decrease in the most contributing classes $(30<$ percentile $<70)$, and consequently in extended winter (October-March) precipitation, is expected in Iberia. Such contrasting precipitation responses are in line with the abovementioned dynamical shift toward an enhanced meridional pressure gradient. With regard to this point, Deser et al. (2017) used another setting of the model (without the carbon cycle included as in our study) showing that CESM is able to realistically represent the precipitation changes in large-scale circulation over the North Atlantic basin. Furthermore, in Iberia, the future projection for the number of simulated wet days drops drastically in transition seasons, especially during autumn. We must however stress the need for further regional analysis, as despite the overall trend expected in Iberia points to drying, some regional intricacies should be expected, especially in areas with more complex terrain, as northernmost sectors of the peninsula (Francés et al. 2017). In summary, this CESM simulation points out to a shortening of the rainy season ensuing the global warming trend. This can have strong implications for the water cycle in the region, particularly for southern Iberia, which is already frequently affected by drought under current climate conditions (Trigo et al. 2013).

To finalize, the authors acknowledge that the results presented here were based on a single simulation, and therefore uncertainties arising from such an approach are very difficult to compute objectively. More robust estimations of such uncertainties should always be obtained by using multimodel approaches and/or ensembles techniques (e.g., Zappa et al. 2013; Santos et al. 2016; Cardoso et al. 2019). Nevertheless, and as discussed previously, the performance of the CESM model in several experiments makes this single-model exercise (as others that could be explored) a very valuable approach for such an extended historical period.

Acknowledgments. The financial support for this work was possible through the following FCT project: HOLMODRIVE-North Atlantic Atmospheric Patterns Influence on Western Iberia Climate: From the Late Glacial to the Present (PTDC/CTA-GEO/29029/2017). The CESM simulation is performed on the supercomputing architecture of the Swiss National Supercomputing Centre (CSCS). Author Ramos was supported by the Scientific Employment Stimulus 2017 from FCT (CEECIND/00027/2017). Author Raible is supported by the Swiss National Science Foundation (SNF; Grant 18001). Author Messmer acknowledges support by the SNF (Early Postdoc.Mobility). Author Pinto thanks the AXA Research Fund for support.

\section{REFERENCES}

Alexander, M. A., J. D. Scott, K. Friedland, K. E. Mills, J. Á. Nye, A. J. Pershing, and A. C. Thomas, 2018: Projected sea surface temperatures over the 21st century: Changes in the mean, variability and extremes for large marine ecosystem regions of Northern Oceans. Elem. Sci. Anthropocene, 6, 9, https:// doi.org/10.1525/elementa.191.

Becker, A., P. Finger, A. Meyer-Christoffr, B. Rudolf, K. Schamm, U. Schneider, and M. Ziese, 2013: A description of the global land-surface precipitation data products of the Global Precipitation Climatology Centre with sample applications including centennial (trend) analysis from 1901-present. Earth Syst. Sci. Data, 5, 71-99, https://doi.org/10.5194/essd-5-712013.

Blamey, R. C., A. M. Ramos, R. M. Trig, R. Tome, and C. J. C. Reason, 2018: The influence of atmospheric rivers over the South Atlantic on winter rainfall in South Africa. J. Hydrometeor. 19, 127-142, https://doi.org/10.1175/JHM-D-17-0111.1.

Bothe, O., and Coauthors, 2015: Continental scale temperature variability in the PMIP3 simulation ensemble and PAGES $2 \mathrm{~K}$ regional temperature reconstructions over the past millennium. Climate Past, 11, 1673-1699, https://doi.org/10.5194/ cp-11-1673-2015.

Bradley, R. S., M. K. Hughes, and H. F. Diaz, 2003: Climate in Medieval time. Science, 302, 404-405, https://doi.org/10.1126/ science.1090372.

Brands, S., J. M. Gutiérrez, and D. San-Martín, 2017: Twentiethcentury atmospheric river activity along the west coasts of Europe and North America: Algorithm formulation, reanalysis uncertainty and links to atmospheric circulation patterns. Climate Dyn., 48, 2771-2795, https://doi.org/10.1007/s00382-016-3095-6.

Byrne, M. P., and P. A. O'Gorman, 2018: Trends in continental temperature and humidity directly linked to ocean warming. Proc. Natl. Acad. Sci. USA, 115, 4863-4868, https://doi.org/ 10.1073/pnas.1722312115. 
Camenisch, C., and Coauthors, 2016: The 1430s: A cold period of extraordinary internal climate variability during the early Spörer Minimum with social and economic impacts in northwestern and central Europe. Climate Past, 12, 2107-2126, https://doi.org/10.5194/cp-12-2107-2016.

Cardoso, R. M., P. M. M. Soares, D. C. A. Lima, and P. M. A. Miranda, 2019: Mean and extreme temperatures in a warming climate: EURO CORDEX and WRF regional climate highresolution projections for Portugal. Climate Dyn., 52, 129-157, https://doi.org/10.1007/s00382-018-4124-4.

Chemke, R., and L. M. Polvani, 2019: Exploiting the abrupt $4 \times$ $\mathrm{CO}_{2}$ scenario to elucidate tropical expansion mechanisms. J. Climate, 32, 859-875, https://doi.org/10.1175/JCLI-D-180330.1.

Chikamoto, M. O., and Coauthors, 2016: Volcanic eruptions boost tropical Pacific biological productivity. Geophys. Res. Lett., $\mathbf{4 3}$, 1184-1192, https://doi.org/10.1002/2015GL067359.

Cook, B. I., J. E. Smerdon, R. Seager, and S. Coats, 2014: Global warming and 21st century drying. Climate Dyn., 43, 2607-2627, https://doi.org/10.1007/s00382-014-2075-y.

_ K. J. Anchukaitis, R. Touchan, D. M. Meko, and E. R. Cook, 2016: Spatiotemporal drought variability in the Mediterranean over the last 900 years. J. Geophys. Res., 121, 2060-2074, https://doi.org/10.1002/2015JD023929.

Dacre, H. F., O. Martínez-Alvarado, and C. O. Mbengue, 2019: Linking atmospheric rivers and warm conveyor belt airflows. J. Hydrometeor., 20, 1183-1196, https://doi.org/10.1175/ JHM-D-18-0175.1.

Deser, C., J. W. Hurrel, and A. S. Phillips, 2017: The role of the North Atlantic Oscillation in European climate projections. Climate Dyn., 49, 3141-3157, https://doi.org/10.1007/ s00382-016-3502-z.

Dettinger, M. D., 2013: Atmospheric rivers as drought busters on the U.S. West Coast. J. Hydrometeor., 14, 1721-1732, https:// doi.org/10.1175/JHM-D-13-02.1.

— - F. M. Ralph, and D. Lavers, 2015: Setting the stage for a global science of atmospheric rivers. Eos, Trans. Amer. Geophys. Union, 96, https://doi.org/10.1029/2015EO038675.

Eiras-Barca, J., A. M. Ramos, J. G. Pinto, R. M. Trigo, M. L. R. Liberato, and G. Miguez-Macho, 2018: The concurrence of atmospheric rivers and explosive cyclogenesis in the North Atlantic and North Pacific basins. Earth Syst. Dyn., 9, 91-102, https://doi.org/10.5194/esd-9-91-2018.

Emori, S., and S. J. Brown, 2005: Dynamic and thermodynamic changes in mean and extreme precipitation under changed climate. Geophys. Res. Lett., 32, L17706, https://doi.org/10.1029/2005GL023272.

Espinoza, V., D. E. Waliser, B. Guan, D. A. Lavers, and F. M. Ralph, 2018: Global analysis of climate change projection effects on atmospheric rivers. Geophys. Res. Lett., 45, 42994308, https://doi.org/10.1029/2017GL076968.

Ferreira, J. A., M. L. R. Liberato, and A. M. Ramos, 2016: On the relationship between atmospheric water vapour transport and extra-tropical cyclones development. Phys. Chem. Earth, 94, 56-65, https://doi.org/10.1016/J.PCE.2016.01.001.

Flint, L. E., A. L. Flint, J. Mendoza, J. Kalansky, and F. M. Ralph, 2018: Characterizing drought in California: New drought indices and scenario-testing in support of resource management. Ecol. Process., 7, 1, https://doi.org/10.1186/s13717-017-0112-6.

Francés, P. A., M. J. C. Calle, A. P. Saavedra, P. R. Calzado, and E. R. Camino, 2017: Guía de escenarios regionalizados de cambio climático sobre España a partir de los resultados del IPCC-AR5 (Guide to regionalized climate change scenarios with regard to Spain based on the IPCC-AR5). Agencia Estatal de
Meteorología Rep., 102 pp., http://www.aemet.es/documentos/es/ conocermas/recursos_en_linea/publicaciones_y_estudios/ publicaciones/Guia_escenarios_AR5/Guia_escenarios_AR5.pdf.

Gimeno, L., and Coauthors, 2016: Major mechanisms of atmospheric moisture transport and their role in extreme precipitation events. Annu. Rev. Environ. Resour., 41, 117-141, https://doi.org/10.1146/annurev-environ-110615-085558.

Gomez-Navarro, J. J., E. Zorita, C. C. Raible, and R. Neukom, 2017: Testing reconstructions of the global mean annual temperature during the Common Era with the analogue method. Climate Past, 13, 629-648, https://doi.org/10.5194/cp-13-629-2017.

Guillet, S., and Coauthors, 2017: Climate response to the Samalas volcanic eruption in 1257 revealed by proxy records. Nat. Geosci., 10, 123-128, https://doi.org/10.1038/ngeo2875.

Harvey, B. J., L. C. Shaffrey, and T. J. Woollings, 2015: Deconstructing the climate change response of the Northern Hemisphere wintertime storm tracks. Climate Dyn., 45, 2847-2860, https://doi.org/10.1007/s00382-015-2510-8.

He, J., and N. J. Soden, 2017: A re-examination of the projected subtropical precipitation decline. Nat. Climate Change, $\mathbf{7}$, 53-57, https://doi.org/10.1038/nclimate3157.

Hecht, C. W., and J. M. Cordeira, 2017: Characterizing the influence of atmospheric river orientation and intensity on precipitation distributions over north-coastal California. Geophys. Res. Lett., 44, 9048-9058, https://doi.org/10.1002/2017GL074179.

Hurrell, J. W., and Coauthors, 2013: The Community Earth System Model: A framework for collaborative research. Bull. Amer. Meteor. Soc., 94, 1339-1360, https://doi.org/ 10.1175/BAMS-D-12-00121.1.

IPCC, 2019: Global Warming of 1.5 ${ }^{\circ}$ C. V. Masson-Delmotte et al., Eds., Cambridge University Press, 630 pp., https://www.ipcc.ch/site/ assets/uploads/sites/2/2019/06/SR15_Full_Report_High_Res.pdf.

Kalnay, E., and Coauthors, 1996: The NCEP/NCAR 40-Year Reanalysis Project. Bull. Amer. Meteor. Soc., 77, 437-471, https:// doi.org/10.1175/1520-0477(1996)077<0437:TNYRP>2.0.CO;2.

Lamb, H. H., 1972: British Isles weather types and a register of daily sequence of circulation patterns, 1861-1971. Geophysical Memoirs, Vol. 116, H.M. Stationery Office, 1861-1971.

Lavers, D. A., and G. Villarini, 2013: The nexus between atmospheric rivers and extreme precipitation across Europe. Geophys. Res. Lett., 40, 3259-3264, https://doi.org/10.1002/grl.50636.

—, and - 2015: The contribution of atmospheric rivers to precipitation in Europe and the United States. J. Hydrol., 522, 382-390, https://doi.org/10.1016/j.jhydrol.2014.12.010.

R. P. Allan, E. F. Wood, G. Villarini, D. J. Brayshaw, and A. J. Wade, 2011: Winter floods in Britain are connected to atmospheric rivers. Geophys. Res. Lett., 38, L23803, https:// doi.org/10.1029/2011GL049783.

, — , G. Villarini, B. Lloyd-Hughes, D. J. Brayshaw, and A. J. Wade, 2013: Future changes in atmospheric rivers and their implications for winter flooding in Britain. Environ. Res. Lett., 8, 034010, https://doi.org/10.1088/1748-9326/8/3/034010.

Lehner, F., K. Keller, C. C. Raible, J. Mignot, A. Born, F. Joos, and T. F. Stocker, 2015: Climate and carbon cycle dynamics in a CESM simulation from 850 to 2100 CE. Earth Syst. Dyn., 6, 411-434, https://doi.org/10.5194/esd-6-411-2015.

Li, M., T. Woolings, K. Hodges, and G. Masato, 2014: Extratropical cyclones in a warmer, moister climate: A recent Atlantic analogue. Geophys. Res. Lett., 41, 8594-8601, https://doi.org/ 10.1002/2014GL062186.

Lorenz, D. J., and E. T. DeWeaver, 2007: The response of the extratropical hydrological cycle to global warming. J. Climate, 20, 3470-3484, https://doi.org/10.1175/JCLI4192.1. 
Lu, J., C. Deser, and T. Reichler, 2009: Cause of the widening of the tropical belt since 1958. Geophys. Res. Lett., 36, L03803, https://doi.org/10.1029/2008GL036076.

Ludwig, P., J. G. Pinto, C. C. Raible, and Y. Shao, 2017: Impacts of surface boundary conditions on regional climate model simulations of European climate during the Last Glacial Maximum. Geophys. Res. Lett., 44, 5086-5095, https://doi.org/ 10.1002/2017GL073622.

Neiman, P. J., F. M. Ralph, G. A. Wick, J. D. Lundquist, and M. D. Dettinger, 2008: Meteorological characteristics and overland precipitation impacts of atmospheric rivers affecting the west coast of North America based on eight years of SSM/I satellite observations. J. Hydrometeor., 9, 22-47, https:// doi.org/10.1175/2007JHM855.1.

Nie, J., A. H. Sobel, D. A. Shaevitz, and S. Wang, 2018: Dynamic amplification of extreme precipitation sensitivity. Proc. Natl. Acad. Sci. USA, 115, 9467-9472, https://doi.org/10.1073/ pnas.1800357115.

Oakley, N., J. Lancaster, B. Hatchett, J. Stock, F. Ralph, S. Roj, and S. Lukashov, 2018: A 22-year climatology of cool season hourly precipitation thresholds conducive to shallow landslides in California. Earth Interact., 22, https://doi.org/10.1175/ EI-D-17-0029.1.

O'Gorman, P. A., and C. J. Muller, 2010: How closely do changes in surface and column water vapor follow Clausius-Clapeyron scaling in climate change simulations? Environ. Res. Lett., 5 , 025207, https://doi.org/10.1088/1748-9326/5/2/025207.

Osborn, T. J., S. Gosling, C. Wallace, and S. Dorling, 2015: The water cycle in a changing climate. Seventh World Water Forum, Words into Action, Faircount Media Group, DaeguGyeongbuk, South Korea, 14-19.

Peixoto, J. P., and A. H. Oort, 1992: Physics of Climate. American Institute of Physics, $520 \mathrm{pp}$.

Pereira, S., A. M. Ramos, L. Rebelo, R. M. Trigo, and J. L. Zêzere, 2018: A centennial catalogue of hydro-geomorphological events and their atmospheric forcing. Adv. Water Resour., 122, 98-112, https://doi.org/10.1016/j.advwatres.2018.10.001.

Pfahl, S., P. A. O'Gorman, and E. M. Fischer, 2017: Understanding the regional pattern of projected future changes in extreme precipitation. Nat. Climate Change, 7, 423-428, https://doi.org/ 10.1038/nclimate3287.

Pinto, J. G., S. Zacharias, A. H. Fink, G. C. Leckebusch, and U. Ulbrich, 2009: Factors contributing to the development of extreme North Atlantic cyclones and their relationship with the NAO. Climate Dyn., 32, 711-737, https://doi.org/10.1007/s00382-008-0396-4.

Raible, C. C., 2007: On the relation between extremes of midlatitude cyclones and the atmospheric circulation using ERA40. Geophys. Res. Lett., 34, L07703, https://doi.org/10.1029/2006GL029084.

—-, M. Yoshimori, T. F. Stocker, and C. Casty, 2007: Extreme midlatitude cyclones and their implications to precipitation and wind speed extremes in simulations of the Maunder Minimum versus present day conditions. Climate Dyn., 28, 409-423, https://doi.org/10.1007/s00382-006-0188-7.

- H. Saaroni, B. Ziv, and M. Wild, 2010: Winter cyclonic activity over the Mediterranean Basin under future climate based on the ECHAM5 GCM. Climate Dyn., 35, 473-488, https://doi.org/10.1007/s00382-009-0678-5.

_ F. Fehner, J. F. Gonzalez-Rouco, and L. Fernandez-Donado, 2014: Changing correlation structures of the Northern Hemisphere atmospheric circulation from 1000 to $2100 \mathrm{AD}$. Climate Past, 10, 537-550, https://doi.org/10.5194/cp-10-537-2014.

—, M. Messmer, F. Lehner, T. F. Stocker, and R. Blender, 2018: Extratropical cyclone statistics during the last millennium and the 21st century. Climate Past, 14, 1499-1514, https://doi.org/ 10.5194/cp-14-1499-2018.

Ralph, F. M., and M. D. Dettinger, 2011: Storms, floods, and the science of atmospheric rivers. Eos, Trans. Amer. Geophys. Union, 92, 265, https://doi.org/10.1029/2011EO320001.

_ - and Coauthors, 2017: Dropsonde observations of total integrated water vapor transport within North Pacific atmospheric rivers. J. Hydrometeor., 18, 2577-2596, https://doi.org/ 10.1175/JHM-D-17-0036.1.

Ramos, A. M., N. Cortesi, and R. M. Trigo, 2014: Circulation weather types and spatial variability of daily precipitation in the Iberia. Front. Earth Sci., 2, 25, https://doi.org/10.3389/ FEART.2014.00025.

— , R. M. Trigo, M. L. R. Liberato, and R. Tomé, 2015: Daily precipitation extreme events in the Iberia and its association with atmospheric rivers. J. Hydrometeor., 16, 579-597, https:// doi.org/10.1175/JHM-D-14-0103.1.

—, R. Nieto, R. Tomé, L. Gimeno, R. M. Trigo, M. L. R. Liberato, and D. A. Lavers, 2016a: Atmospheric rivers moisture sources from a Lagrangian perspective. Earth Syst. Dyn., 7, 371-384, https://doi.org/10.5194/esd-7-371-2016.

— , R. Tomé, R. M. Trigo, M. L. R. Liberato, and J. G. Pinto, 2016b: Projected changes in atmospheric rivers affecting Europe in CMIP5 models. Geophys. Res. Lett., 43, 93159323, https://doi.org/10.1002/2016GL070634.

_ , R. C. Blamey, I. Algarra, R. Nieto, L. Gimeno, R. Tomé, C. J. C. Reason, and R. M. Trigo, 2018: From Amazonia to southern Africa: Atmospheric moisture transport through low level jets and atmospheric rivers. Ann. N. Y. Acad. Sci., 1436, 217-230, https://doi.org/10.1111/NYAS.13960.

Santos, J. A., M. Belo-Pereira, H. Fraga, and J. G. Pinto, 2016: Understanding climate change projections for precipitation over western Europe with a weather typing approach. J. Geophys. Res. Atmos., 121, 1170-1189, https://doi.org/ 10.1002/2015JD024399.

Schmidt, G. A., and Coauthors, 2012: Climate forcing reconstructions for use in PMIP simulations of the Last Millennium (v1.1). Geosci. Model Dev., 5, 185-191, https://doi.org/10.5194/ gmd-5-185-2012.

Schneider, T., P. A. O'Gorman, and X. J. Levine, 2010: Water vapor and the dynamics of climate changes. Rev. Geophys., $\mathbf{4 8}$ RG3001, https://doi.org/10.1029/2009RG000302.

Seager, R., N. Naik, and G. A. Vecchi, 2010: Thermodynamic and dynamic mechanisms for large-scale changes in the hydrological cycle in response to global warming. J. Climate, $\mathbf{2 3}$, 4651-4668, https://doi.org/10.1175/2010JCLI3655.1.

Sherwood, S. C., W. Ingram, Y. Tsushima, M. Satoh, M. Roberts, P. L. Vidale, and P. A. O'Gorman, 2010: Relative humidity changes in a warmer climate. J. Geophys. Res., 115, D09104, https://doi.org/10.1029/2009JD012585.

Skliris, N., J. D. Zika, G. Nurser, S. A. Josey, and R. Marsh, 2016: Global water cycle amplifying at less than the ClausiusClapeyron rate. Nat. Sci. Rep., 6, 38752, https://doi.org/ 10.1038/srep38752.

Sodemann, H., and A. Stohl, 2013: Moisture origin and meridional transport in atmospheric rivers and their association with multiple cyclones. Mon. Wea. Rev., 141, 2850-2868, https:// doi.org/10.1175/MWR-D-12-00256.1.

Sousa, P. M., R. C. Blamey, C. J. C. Reason, A. M. Ramos, and R. M. Trigo, 2018: The 'Day Zero' Cape Town drought and the poleward migration of moisture corridors. Environ. Res. Lett., 13, 124025, https://doi.org/10.1088/1748-9326/ aaebc7. 
Staten, P. W., J. J. Rutz, T. Reichler, and J. Lu, 2012: Breaking down the tropospheric circulation response by forcing. Climate Dyn., 39, 2361-2375, https://doi.org/10.1007/s00382-011-1267-y.

_, J. Lu, K. M. Grise, S. M. Davis, and T. Birner, 2018: Reexamining tropical expansion. Nat. Climate Change, 8, 768-775, https://doi.org/10.1038/s41558-018-0246-2.

Taylor, K. E., R. J. Stouffer, and G. A. Meehl, 2012: An overview of CMIP5 and the experiment design. Bull. Amer. Meteor. Soc. 93, 485-498, https://doi.org/10.1175/BAMS-D-11-00094.1.

Trigo, R. M., and C. C. DaCamara, 2000: Circulation weather types and their influence on the precipitation regime in Portugal. Int. J. Climatol., 20, 1559-1581, https://doi.org/10.1002/10970088(20001115)20:13<1559::AID-JOC555>3.0.CO;2-5.

, and Coauthors, 2013: The record winter drought of 2011-12 in the Iberian Peninsula [in "Explaining Extreme Events of 2012 from a Climate Perspective'']. Bull. Amer. Meteor. Soc., 94 (9), S41-S45, https://doi.org/10.1175/BAMS-D-13-00085.1.

Ulbrich, U., G. C. Leckebusch, and J. G. Pinto, 2009: Extra-tropical cyclones in the present and future climate: A review. Theor.
Appl. Climatol., 96, 117-131, https://doi.org/10.1007/s00704008-0083-8.

Viale, M., R. Valenzuela, R. D. Garreaud, and F. M. Ralph, 2018: Impacts of atmospheric rivers on precipitation in southern South America. J. Hydrometeor., 19, 1671-1687, https://doi.org/ 10.1175/JHM-D-18-0006.1.

Zappa, G., L. C. Shaffrey, K. I. Hodges, P. G. Sansom, and D. B. Stephenson, 2013: A multimodel assessment of future projections of North Atlantic and European extratropical cyclones in the CMIP5 climate models. J. Climate, 26, 5846-5862, https://doi.org/10.1175/JCLI-D-12-00573.1.

, B. J. Hoskins, and T. G. Shepherd, 2015: Improving climate change detection through optimal seasonal averaging: The case of the North Atlantic jet and European precipitation. J. Climate, 28, 6381-6397, https://doi.org/10.1175/JCLI-D-14-00823.1.

Zhu, Y., and R. E. Newell, 1998: A proposed algorithm for moisture fluxes from atmospheric rivers. Mon. Wea. Rev., 126, 725-735, https://doi.org/10.1175/1520-0493(1998)126<0725:APAFMF> 2.0.CO;2. 